\title{
Advances in sports nutrition, exercise and medicine: Olympic issues, the legacy and beyond
}

\author{
Mike Carmont
}

\begin{abstract}
In the run up to the London 2012 Olympics, this editorial introduces the cross-journal article collection Advances in Sports Nutrition, Exercise and Medicine http://www.biomedcentral.com/series/asnem
\end{abstract}

\section{Editorial}

Since 2006, Sports and Exercise Medicine (SEM) in the United Kingdom has developed from General Practitioners with specialist interests and those from other allied specialties, to a specialization within its own right and the formation of its own Faculty. The progression of this specialty has gone hand in hand with preparations for the Olympic Games in London commencing $27^{\text {th }}$ July 2012.

Now, in the run up to the Games, SEM practitioners are completing preparations for the competition itself and are starting to look towards the continued care of the athletes and teams.

Within the UK, recent cardiac events have resulted in both tragedy and successful resuscitation. The cardiac arrest of a Premier League Footballer during a match has led to calls for the cardiac screening of all professional footballers in the UK. Italian studies have shown that the screening of athletes for the presence of cardiac abnormalities prior to sports participation has led to a reduction in mortality in this cohort [1-3].

For players with no family history or detectable underlying cardiac abnormality, screening may not have prevented this cardiac arrest. The quick response of the team doctors and physiotherapists trained, practiced and prepared for cardiac events at the pitch side without doubt lead to improved outcome. It is well known that there is a $10 \%$ reduction in outcome for each minute that passes before defibrillation [4]. Good quality cardiopulmonary resuscitation is a skill, which everyone can learn and this preserves perfusion to the brain [5]. There has also been discussion

Correspondence: mcarmont@hotmail.com

The Princess Royal Hospital, Shrewsbury \& Telford NHS Trust and the Northern General Hospital, Sheffield Teaching Hospitals NHS Foundation Trust, Sheffield, UK as to whether resuscitation should be performed on the pitch. While, these scenes may appear distressing for the spectators, not witnessing this care may be more distressing in the long term.

The tragic death of a school-girl hit in the chest by a rugby ball has highlighted discrepancies between the provision of emergency care on the school playing field and the professional game. This rare event, Commotio cordis, occurs when the force of the impact occurs precisely on the upstroke of the $\mathrm{T}$ wave when the heart is repolarising and an arrhythmia develops [5]. It was recently appreciated that it is not the force of this impact but the unfortunate precision of the impact [6]. Once again screening would not have prevented this as Commotio cordis occurs in hearts that are structurally and electrophysiologically normal. Prompt defibrillation, if available, even by bystanders, can restore cardiac output [7]. It may be, however, that the adoption of a screening programme together with the availability of defibrillators at sporting events is the optimal course of prevention and preparation for sudden cardiac events during sports $[3,8]$.

Preparation also includes the avoidance of injury, which was the subject of a systematic review [9] reviewing a number of neuromuscular warm up strategies to prevent lower limb and knee injuries. The 11+, Prevent injury and Enhance Performance (PEP), Harmoknee and Knee Injury Prevention Programme (KIPP) all feature components of stretching, strengthening, balance, sports specific agility drills and landing techniques for periods of 3 months. It is hoped that injuries such as anterior cruciate ligament rupture and their sequelae will be minimized by the adoption of these programmes.

Over the course of the 2012 Olympic Games, we will witness athletes performing faster, higher and stronger than their predecessors. This may pose a couple of 
questions. Firstly, how far is an athlete prepared to go to get an advantage? Secondly, how much are they prepared to use and possibly abuse their bodies to win?

The impact of these effects can be observed both in the short and long term. The World Anti-Doping Agency is an international independent organization responsible for promoting, co-ordinating and monitoring the fight against doping in sport. The agency produces a list of banned substances each year called The Prohibited List [10]. It must be remembered that in every case the athlete has full responsibility for everything that goes into their body. Information about substances is readily available for athletes on sites such as 100 percentme [11] and the prohibited list is even available as an iphone application [12].

One legal way in which performance can be enhanced is by some forms of dietary supplementation. For instance, betaine supplementation has been shown to increase cycling sprint power in recreationally active males and females [13]. Moreover, the optimization of diet prior to commencing an exercise programme is important. Military recruits sustaining stress fractures during elite military training were found to have previous dietary deficiencies compared to those who were injury free [14]. However, those skeptical about the ability of sports drinks to rehydrate and improve performance will be interested in Kalman's recent study. After being dehydrated to a $2 \%$ reduction in body mass during a 60 minute bout of treadmill exercise, subjects showed little difference in a subsequent exercise to exhaustion test after rehydrating with bottled water, coconut water, coconut water concentrate or sports drink [15].

Many interventions can aim to enhance performance, but in the end, the athlete's efforts will be the culmination of hours of training and preparation. It is now appreciated that elite athletes may suffer long-term degenerative joint disease as a result of their hours of training [16]. The early management of these patients may well be able to postpone definitive joint replacement surgery. Symptom alleviation by intra-articular injections of corticosteroid, hyaluronic acid (HA) and platelet rich plasma (PRP) are attractive options.

Injections of HA may act as both a mechanical lubricant and act biologically to stimulate the synoviocytes to produce synovial fluid with improved the physical properties. Meta-analyses have suggested peak effectiveness at 8 weeks following injection and that there is still a residual detectable effect after 24 weeks [17]. HA injections are more effective than corticosteroid injections beyond 8 weeks following injection [18].

PRP injections are specific fractions of centrifuged autologous blood and may be injected to prevent deterioration and promote regeneration of the articular surface [19]. PRP releasate has been shown to inhibit the inflammatory processes in osteoarthritic chondrocytes and decreases activation in the pathways involved in the pathogenesis of osteoarthritis [20]. PRP injections have also been shown to provide a greater and longer efficacy than HA injections in reducing symptoms and the recovery of articular function [21]. It must be remembered that when discussing the effectiveness of PRP that there are numerous methods of preparation of PRP and preparations rich in growth factors. Thus treatment using PRP will vary considerably in different studies [22].

Strategies to promote recovery are not limited just to athletes. With joints frequently wearing out at a younger age when patients have busy, working, and productive lives, definitive strategies may have to be adopted. Degeneration may only occur in part of a joint e.g. the medial compartment of the knee. Re-alignment osteotomy may prolong the life expectancy of the patient's native joint by offloading this area [23] and may be comparable to a partial joint replacement [24]. Patients always ask about future function before surgery. Although patients may return to sporting activity, they do not perform at their previous level and residual pain is not exceptional [25]. Alternatively biological knee reconstruction may be considered as a viable option [26].

In a similar vein, the influence of the Games stretches to the general public, and not just the athletes involved. Its influence in promoting health and exercise is something that has been considered since the Games were awarded to the city of London in 2007 [27]. The "Legacy" of the Olympic Games is promoted to encourage sports participation in the home nation. In this way, it is hoped that the general population can receive the benefits of sports participation for health and exercise, and this legacy has been considered to involve both the sports' community and the general community [28]. Three Olympic Legacy centres for Sports and Exercise Medicine have been selected to receive funding from the government to build SEM services in London, Loughborough and Sheffield [29]. Considering the difficulty of the current economic situation, the allocation of resources to leisure activities could be considered to be an expensive luxury. However, the promotion of health and exercise may save money in the long term as there is likely to be a higher degree of physical activity, and therefore a lower incidence of morbidities associated with the sedentary lifestyle to which many of us have become accustomed. It should be noted, however, that the success of this legacy requires the public to take up the exercise challenge so that the benefits can be appreciated for both the individual and the nation [30].

\section{Authors' information}

MC is a Consultant Trauma and Orthopaedic Surgeon with an interest in lower limb sports surgery and sports medicine. He is volunteering to 
provide medical services for the Olympic Games. He is also the Guest Editor for the Advances in Sports Nutrition, Exercise and Medicine cross-journal article collection.

Received: 17 July 2012 Accepted: 19 July 2012 Published: 19 July 2012

\section{References}

1. Asif IM, Drezner JA: Sudden cardiac death and preparticipation screening: the debate continues-in support of electrocardiogram-inclusive preparticipation screening. Prog Cardiovasc Dis 2012, 54(5):445-50.

2. Shephard RJ: Mandatory ECG screening of athletes: is this question now resolved? Sports Med 2011, 41(12):989-1002.

3. Corrado D, Drezner J, Basso C, Pelliccia A, Thiene G: Strategies for the prevention of sudden cardiac death during sports. Eur J Cardiovasc Prev Rehabil 2011, 18(2):197-208.

4. White RD, Asplin BR, Bugliosi TF, Hankins DG: High discharge survival rate after out of hospital ventricular fibrillation with rapid defibrillation by police and paramedics. Ann Emerg Med 1996, 285:480-5

5. Advanced Life Support Course Manual. Resuscitation Council UK, 62011.

6. Kalin J, Madias C, Alsheikh-Ali AA, Link MS: Reduced diameter spheres increases the risk of chest blow induced ventricular fibrillation (commotio cordis). Heart Rhythm 2011, 8(10):1578-81.

7. Ngai KY, Chan HY, Ng F: A patient with commotio cordis successfully resuscitated by bystander cardiopulmonary resuscitation and automated external defibrillator. Hong Kong Med J 2010, 16(5):403-5.

8. Borjesson M, Serratosa L, Carre F, Corrado D, Drezner J, Dugmore DL, Heidbuchel HH, Mellwig KP, Panhuyzen-Goedkoop NM, Papadakis M, Rasmusen H, Sharma S, Solberg EE, van Buuren F, Pelliccia A, writing group on behalf of the EACPR Section of Sports Cardiology: Consensus document regarding cardiovascular safety at sports arena: position stand from the European Association of Cardiovascular Prevention and Rehabilitation (EACPR), section of Sports Cardiology. Eur Heart J 2011, 32(17):2119-24.

9. Herman K, Barton C, Malliaras P, Morrissey D: The effectiveness of neuromuscular warm-up strategies, that require no additional equipment, for preventing lower limb injuries during sports participation: a systematic review. BMC Medicine 2012, 10:75.

10. The World Anti-Doping Code. The 2012 Prohibited List International Standard. [http://list.wada-ama.org/].

11. What is $100 \%$ me?. [http://www.ukad.org.uk/athletes/100 percentme] Accessed 29/03/2012.

12. WADA Prohibited List Itunes App. [http://itunes.apple.com/us/app/wadaprohibited-list-2011/id408057950?mt=8]

13. Pryor $J$, Craig SAS, Swensen T: Effect of betaine supplementation on cycling sprint performance. Journal of the International Society of Sports Nutrition 2012, 9:12.

14. Moran DS, Heled $Y$, Arbel $Y$, Israeli E, Finestone AS, Evans RK, Yanovich R: Dietary intake and stress fractures among elite male combat recruits. Journal of the International Society of Sports Nutrition 2012, 9:6.

15. Kalman DS, Feldman S, Krieger DR, Bloomer RJ: Comparison of coconut water and a carbohydrate-electrolyte sport drink on measures of hydration and physical performance in exercise-trained men. Journal of the International Society of Sports Nutrition 2012, 9:1.

16. Tveit M, Rosengren BE, Nilsson JA, Karlsson MK: Former male elite athletes have a higher prevalence of osteoarthritis and arthroplasty in the hip and knee than expected. Am J Sports Med 2012, 40(3):527-33.

17. Bannuru RR, Natav NS, Dasi UR, Schmid CH, McAlendon TE: Therapeutic trajectory following intra-articular hyaluronic acid injection in knee osteoarthritis: a meta-analysis. Osteoarthritis Cartilage 2011, 19(6):611-9.

18. Bannuru RR, Natov NS, Obadon IE, Price LL, Schmid CH, McAlendon TE: Therapeutic trajectory of hyaluronic acid versus corticosteroids in the treatment of knee osteoarthritis: a systematic review and meta-analysis. Arthritis Rheum 2009, 61(12):1704-11

19. Andia I, Sanchez M, Maffulli N: Joint pathology and platelet rich plasma therapies. Expert Opin Biol Ther 2012, 12(1):7-22.

20. Van Buul GM, Koevaet WL, Kaps N, Bos PK, Verhaar JA, Wienans H, Bernsen MR, van Osch GJ: Platelet rich plasma releasate inhibits inflammatory processes in osteoarthritic chondrocytes. Am J Sports Med 2011, 39(11):2362-70

21. Kon E, Mandelbaum B, Buda R, Filardo G, Delcogliano M, Timoncini A, Fornasari PM, Giannini S, Marcacci M: Platelet rich plasma intra-articual injection versus hyaluronic acid viscosupplementation as treatments for cartilage pathology: from early degeneration to osteoarthritis. Arthroscopy 2011, 27(11):1490-501

22. Castillo TN, Pouliot MA, Kim HJ, Dragoo JL: Comparison of growth factor and platelet concentration from commercial platelet rich plasma separation systems. Am J Sports Med 2011, 39(2):266-71.

23. Haviv B, Bronak S, Thein R, Kidron A, Thein R: Mid-term outcome of opening wedge high tibial osteotomy for varus arthritic knees. Orthopedics 2012, 35(2):e192-6.

24. Spahn G, Hofmann GO, von Engelhardt LV, Li M, Neubauer H, Klinger HM: The impact of a high tibial valgus osteotomy and unicompartmental arthroplasty on the treatment for knee osteoarthritis: a meta-analysis. Knee Surg Sports Traumatol Arthrosc 2011.

25. Bonnin MP, Laurent JR, Zadegan F, Badet R, Pooler Archbold HA, Servien E: Can patients really participate in sport after high tibial osteotomy? Knee Surg Sports Traumatol Arthrosc 2011.

26. Harris JD, Cavo M, Brophy R, Siston F, Flanigan D: Biological knee reconstruction: a systematic review of combined mensical allograft transplantation and cartilage repair or restoration. Arthroscopy 2011, 27(3):409-18.

27. Shipway R: Sustainable legacies for the 2012 Olympic Games. J R Soc Promot Health 2007, 127(3):119-24.

28. White $\mathrm{C}$ : Hopes for a health legacy from the Olympic games should focus on the community not sport says expert. BMJ 2011, 343:d4204.

29. $£ 10$ million Sports Medicine Centre of Excellence announced in Sheffield. [http://www.shef.ac.uk/mediacentre/2012/sports-medicine-centre html], Accessed 29/03/2012.

30. Tew GA, Copeland RJ, Till SH: Sport and exercise medicine and the Olympic health legacy. BMC Medicine 2012, 10:74.

\section{Pre-publication history}

The pre-publication history for this paper can be accessed here: http://www.biomedcentral.com/1741-7015/10/79/prepub

doi:10.1186/1741-7015-10-79

Cite this article as: Carmont: Advances in sports nutrition, exercise and medicine: Olympic issues, the legacy and beyond. BMC Medicine 2012 10:79.

\section{Submit your next manuscript to BioMed Central and take full advantage of:}

- Convenient online submission

- Thorough peer review

- No space constraints or color figure charges

- Immediate publication on acceptance

- Inclusion in PubMed, CAS, Scopus and Google Scholar

- Research which is freely available for redistribution 